\title{
Article \\ Systemic Delivery of hGhrelin Derivative by Lyophilizate for Dry Powder Inhalation System in Monkeys
}

\author{
Kahori Miyamoto, Yuko Ishibashi, Tomomi Akita and Chikamasa Yamashita * \\ Department of Pharmaceutics and Drug Delivery, Faculty of Pharmaceutical Sciences, \\ Tokyo University of Science, 2641 Yamazaki, Noda, Chiba 278-8510, Japan; 3A17706@ed.tus.ac.jp (K.M.); \\ j3a08010@ed.tus.ac.jp (Y.I.); akitat@rs.tus.ac.jp (T.A.) \\ * Correspondence: chikamasa_yamashita@rs.tus.ac.jp; Tel.: +81-4-7124-1501
}

Citation: Miyamoto, K.; Ishibashi, Y.; Akita, T.; Yamashita, C. Systemic Delivery of hGhrelin Derivative by Lyophilizate for Dry Powder Inhalation System in Monkeys. Pharmaceutics 2021, 13, 233. https://doi.org/10.3390/ pharmaceutics13020233

Academic Editor: Anne Marie Healy Received: 15 January 2021

Accepted: 4 February 2021

Published: 7 February 202

Publisher's Note: MDPI stays neutral with regard to jurisdictional claims in published maps and institutional affiliations.

Copyright: (c) 2021 by the authors. Licensee MDPI, Basel, Switzerland. This article is an open access article distributed under the terms and conditions of the Creative Commons Attribution (CC BY) license (https:/ / creativecommons.org/licenses/by/ $4.0 /)$.

\begin{abstract}
Ghrelin is the peptide that increases the hunger sensation and food intake and is expected to be clinically applied for treatment of diseases such as cachexia and anorexia nervosa. In the clinical application of ghrelin, injections are problematic in that they are invasive and inconvenient. Thus, we aimed to develop a formulation that can eliminate the need for injections and can be applied clinically. We prepared formulations of an hGhrelin derivative, in which the octanoyl group essential for expression of activity is modified to avoid rapid des-acylation, using lyophilizate for a dry powder inhalation (LDPI) system. The formulation of hGhrelin derivative was optimized by the addition of phenylalanine, of which the fine particle fraction of $5 \mu \mathrm{m}$ or less was $41.7 \pm 3.8 \%$. We also performed pharmacokinetic/pharmacodynamic tests in monkeys using the optimum formulation that can be applied clinically. The absolute bioavailability of inhaled hGhrelin derivative with respect to that intravenously injected was $16.9 \pm 2.6 \%$. An increase in growth hormone was shown as an effect of the inhaled hGhrelin derivative similar to intravenous injection. The LDPI formulation can deliver the hGhrelin derivative systemically, and it is expected to be applied clinically as a substitute for injections.
\end{abstract}

Keywords: hGhrelin derivative; dry powder inhalation; systemic delivery; monkey; pulmonary administration

\section{Introduction}

Ghrelin is the only currently known peripherally produced peptide that increases hunger sensation and food intake [1-3]. Ghrelin was first isolated from rat and human stomachs in 1999 as a growth hormone secretagogue (GHS) [4]. Ghrelin is an endogenous ligand and acts through the GHS-receptor (GHSR) [4,5]. Ghrelin having a similar primary structure was isolated not only from rat and human but also from many vertebrates such as mouse and bullfrog [6-9]. Human ghrelin (hGhrelin) is a peptide hormone of 28 amino acids, and its activity is expressed by $O-n$-octanoylation at the 3 rd serine residue $[4,6,10]$. Ghrelin is a multifaceted peptide hormone $[6,11]$. Effects on growth hormone $(\mathrm{GH})$ release and appetite are well known as effects of ghrelin that are involved in the regulation of food intake and energy balance $[5,6,12,13]$. Ghrelin increases food intake by stimulation of the appetite through the orexigenic neuropeptide $Y$ /agouti-related protein neurons of the arcuate nucleus in the hypothalamus [14,15]. Because of its anabolic effects (stimulation of appetite, adiposity, and blood glucose), ghrelin is expected to be clinically applied for treatment of diseases such as cachexia and anorexia nervosa [16-18], and clinical trials for the treatment of eating disorders and cachexia with rapid intravenous injection of ghrelin were conducted $[19,20]$. Long-term administration of ghrelin is necessary for treatment of its target diseases such as cachexia and eating disorders. Therefore, development of less stressful formulations of ghrelin is desirable. Peptide drugs are predominantly administered by either intravenous or subcutaneous injection, but parenteral injection is not the preferred route of administration due to pain, risk of infection, and low patient compliance 
in general [21-23]. Moreover, safety issues related to the disposal of needles discourage parenteral administration [22]. Most people with eating disorders and cachexia receive their treatment in an outpatient setting [24]. Injections are likely to require frequent hospital visits leading to increased burden on patients. Especially in regard to eating disorders, resistance to treatment and the high rate of dropouts from treatment are problems [25-30]. The disadvantages of injections decrease motivation for treatment, and thus, injections are not preferable for treatment of eating disorders and cachexia.

Inhalation is one of the dosage forms that can solve the problems of injections [22,31]. In the present study, we decided to develop an inhaled product as a substitute for injections based on the following: (1) The lungs have a large surface area. The total surface area of the alveoli is $100-140 \mathrm{~m}^{2}$, half the area of a tennis court $\left(260 \mathrm{~m}^{2}\right)$. (2) The concentration of metabolic enzymes is lower in lungs than in the gastrointestinal tract. (3) Once drugs deposit in the alveolar region, rapid drug absorption avoiding the hepatic first-pass effect occurs because the alveoli epithelium is close to the systemic circulation compared to other epithelia $[32,33]$. Pulmonary delivery is the only route of administration that meets the above three features; hence, inhaled products are considered to be the most preferable formulation for systemic absorption of peptides of large molecular weight that are easily biodegraded. Therefore, we focused on dry powder inhalers (DPIs) that are non-invasive and convenient from the viewpoint of both less burden on patients and better systemic absorption. Regarding the regulatory issues, tests for uniformity of delivered dose and aerodynamic particle size measurement are mainly required for inhaled products in pharmacopeias. It is difficult to say that inhaled products are strictly regulated compared to other non-injection formulations such as oral preparations or nasal products although more strict evaluations of the in vitro equivalence are required for generic inhaled products. From another viewpoint of pharmacopeias and good manufacturing practice, inhaled products are considered as more preferable dosage forms than injection. Inhaled products require less strict management than injectables because inhaled products do not fall into the realm of sterile products. However, unlike other dosage forms, inhalants are dosage forms that are established as an inhalation system that combines a formulation and an inhalation device. Currently available inhalation systems can be divided into three principal categories: nebulizers, pressurized metered-dose inhalers, and DPIs. Among these, DPIs have attracted attention due to their convenience and because of environmental considerations [33-35]. Dry powder formulations for inhalation are widely manufactured by jet milling or spray-drying. However, peptides and proteins are exposed to the risk of degradation and denaturation due to shear stress or high temperature during the manufacturing process using these methods [36-38]. Thus, we focused on the system developed by Yamashita et al. [39-44], termed lyophilizate for dry powder inhalation (LDPI). In LDPI system, a freeze-dried cake with a porous matrix structure is broken into particles suitable for pulmonary administration by the impact of air introduced in synchronization with the patient's inspiration (Figure 1). LDPI formulations are prepared by a very simple method of lyophilization in which a glass vial is filled with the preparation solution that is then freeze-dried. Therefore, LDPI system is expected to enable pulmonary formulations of heat-sensitive drugs such as peptides and proteins [42,43,45]. 


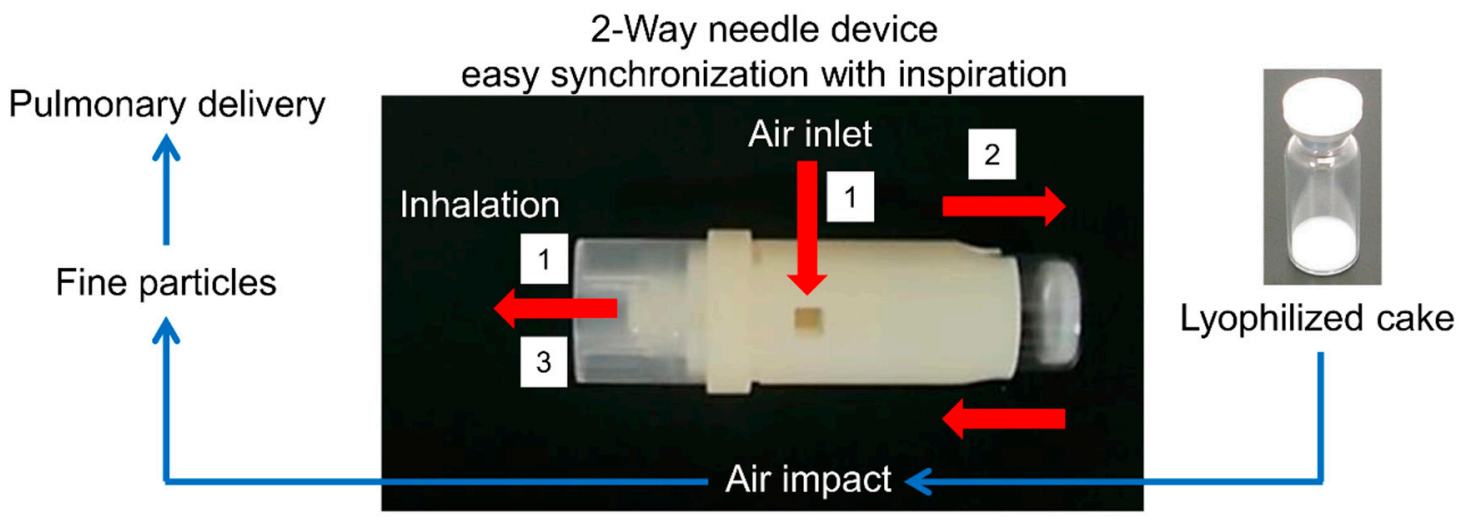

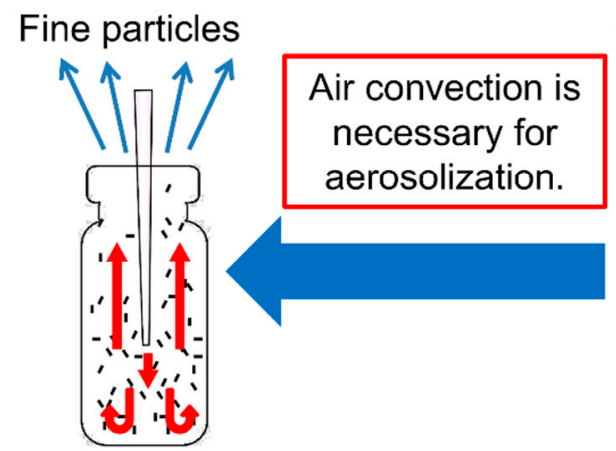

Dispersion

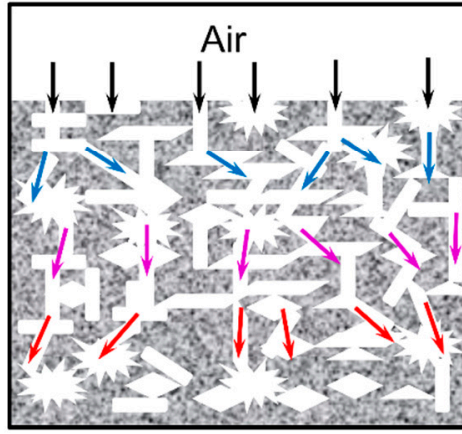

Porous matrix structure

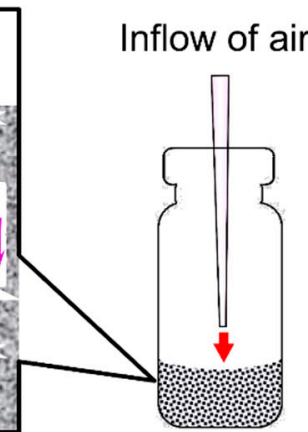

Lyophilized cake

Figure 1. Lyophilizate for dry powder inhalation (LDPI) system. In this novel dry powder inhaler using a two-way needle device, air is introduced into the vial in synchronization with the patient's inhalation through the two-way needle device. Then, lyophilizate with a porous matrix structure is broken into pieces by air impact and aerosolized by the convection flow of air in the vial. Finally, porous particles reconstructed from pieces of lyophilizate are emitted through the device. LDPI formulations with the two-way needle device were used for characteristic inhalation tests by multi-stage liquid impinger. LDPI formulations with another device, which is described later, were used for pharmacokinetic/pharmacodynamic tests in monkeys.

Ghrelin is known to be easily des-acylated in blood plasma because the ester bond is easily cleaved [46,47], although acylation at the 3rd serine residue is necessary for expression of activity. Therefore, we focused on the hGhrelin derivative [48,49]. The ester bond or the lipidic regions of hGhrelin derivative are modified (Figure S1) so that it is less likely to be des-acylated [48,50,51].

From this background, we aimed to develop a clinical powder inhalation formulation of hGhrelin derivative for use with the LDPI system that can solve the problems of injections. We also conducted pharmacokinetic/pharmacodynamic tests in monkeys using the developed LDPI formulation, which can be used clinically to evaluate its feasibility for clinical application.

\section{Materials and Methods}

\subsection{Materials}

hGhrelin derivative was obtained from Asubio Pharma (Kobe, Japan). The following six amino acids (special grade) — L-alanine (Ala), L-methionine (Met), L-phenylalanine (Phe), L-leucine (Leu), L-valine (Val), and L-isoleucine (Ile), $1 \mathrm{~mol} / \mathrm{L}$ hydrochloride ( $\mathrm{HCl}$, special grade), benzalkonium chloride, acetic acid (for volumetric analysis), acetonitrile (HPLC [high-performance liquid chromatography] grade), trifluoroacetic acid (TFA, HPLC grade), disodium hydrogen phosphate (special grade), sodium dihydrogen phosphate (special grade), sodium chloride (special grade), sodium azide (special grade), and albumin from bovine serum (BSA, for biochemistry) were all purchased from Fujifilm Wako Pure Chemi- 
cal Industries (Osaka, Japan). Isoflurane was purchased from Mylan Seiyaku Ltd. (Tokyo, Japan). Disodium ethylenediaminetetraacetic acid dihydrate (EDTA, special grade) was purchased from Dojindo Laboratories (Kamimashiki, Japan). Triton ${ }^{\circledR}-\mathrm{X}$ was purchased from Nacalai Tesque (Kyoto, Japan). Pefabloc ${ }^{\circledR}$ SC (4-(2-aminoethyl)benzenesulfonyl fluoride) was purchased from Roche Applied Sciences (Penzberg, Bayern, Germany). Isotonic sodium chloride solution (saline) was purchased from Otsuka Pharmaceutical (Tokyo, Japan).

The packaging materials used in this study were obtained from the following commercial vendors: 2-mL VIST glass vials from Daiwa Special Glass (Osaka, Japan) and rubber stoppers (F5-43) from Sumitomo Rubber Industries (Kobe, Japan).

The catheter (SAFEED ${ }^{\circledR}$ Nelaton catheter with adaptor $14 \mathrm{Fr}$ ) was purchased from Terumo (Tokyo, Japan).

\subsection{Preparation of Freeze-Dried Cake for Inhalation of hGhrelin Derivative}

Stock solutions of amino acids were prepared by dissolving them in purified water $(10 \mathrm{mg} / \mathrm{mL})$. hGhrelin derivative was dissolved in purified water, and then stock solutions of the amino acids were added. These solutions containing hGhrelin derivative and amino acids were diluted with purified water to obtain the target concentration. $\mathrm{HCl}$ at $1 \mathrm{~mol} / \mathrm{L}$ was added to the diluted solution to adjust $\mathrm{pH}$ to $3-4$. Then, $500 \mu \mathrm{L}$ of the solution was added to a vial and lyophilized by a benchtop freeze dryer (FreeZone Triad 7400030, LABCONCO, Kansas City, MO, USA). The lyophilization conditions were as follows. Shelf cooling was performed from room temperature to $-70{ }^{\circ} \mathrm{C}\left(\leq 0.5^{\circ} \mathrm{C} / \mathrm{min}\right)$, and shelf temperature was held at $-70^{\circ} \mathrm{C}$ for $3 \mathrm{~h}$. Primary drying was performed at a shelf temperature of $-30^{\circ} \mathrm{C}$ and pressure of $1.0 \mathrm{~Pa}$ for $11 \mathrm{~h}$. In the secondary drying step, shelf temperature was ramped to $35^{\circ} \mathrm{C}\left(0.17^{\circ} \mathrm{C} / \mathrm{min}\right)$ for $5 \mathrm{~h}$ and then decreased to $25^{\circ} \mathrm{C}$ $\left(0.34^{\circ} \mathrm{C} / \mathrm{min}\right)$ for $1 \mathrm{~h}$.

\subsection{Quantification of hGhrelin Derivative by HPLC}

HPLC (Prominence series, Shimadzu, Kyoto, Japan) was used to quantify the hGhrelin derivative according to a previous study [52]. Sample solution was applied in a TSKgel ODS-80Ts column $(150 \times 4.6 \mathrm{~mm}, 3 \mu \mathrm{m}$; TOHSO, Tokyo, Japan $)$ at a temperature of $40{ }^{\circ} \mathrm{C}$ and flow rate of $1.0 \mathrm{~mL} / \mathrm{min}$. The concentration gradient of the mobile phase was controlled as follows: from $90 \%$ mobile phase A ( $0.1 \%$ aqueous solution of TFA) and $10 \%$ mobile phase B (0.085\% TFA in acetonitrile); $10 \mathrm{~min}, 24 \%$ mobile phase B; $25 \mathrm{~min}, 30 \%$ mobile phase B; 26-29 min, 70\% mobile phase B. hGhrelin derivative was detected by UV absorption photometer at a wavelength of $214 \mathrm{~nm}$. The limits of detection and quantitation were 0.1 and $1.5 \mu \mathrm{g} / \mathrm{mL}$, respectively.

\subsection{Visual Evaluation of Cake Appearance}

In lyophilized formulations, the lyophilized cake is often required to have a good appearance without cracks or chips [53]. In the LDPI system, a freeze-dried cake with good appearance is necessary to ensure stable performance. Thus, the cake appearance was evaluated by configuration score.

The freeze-dried cake was classified into three types according to appearance: configuration score 0,1 or 2. Configuration score 0 indicates that no cake was formed. Configuration score 1 indicates that the appearance of the cake was not suitable because cracks or chips were observed. Configuration score 2 indicates that a cake without cracks or chips was formed and that its appearance was suitable for the LDPI formulation.

\subsection{Particle Size Distribution}

It is ideal to evaluate all samples by inhalation characteristic tests, but such tests require much time even for only a few samples. In screening studies, we measured the particle size distribution by aerodynamic particle sizer (APS) to optimize formulations 
in a shorter time. The result of APS was used as a surrogate benchmark for inhalation characteristic tests by multi-stage liquid impinger (MSLI).

\subsubsection{Aerodynamic Particle Size Distribution by APS Spectrometer}

We have developed a measurement method using APS in which the APS results can be used to estimate the MSLI results [44], and APS measurement was performed by this method (Figure 2). Briefly, to set the dispersion condition for APS measurement to match that for MSLI measurement, a custom-made glass throat was placed on top of the aerosol diluter of the APS (flow rate $5 \mathrm{~L} / \mathrm{min}$; Model 3302A, TSI, Shoreview, MN, USA), and a linear vacuum pump (flow rate adjusted to $25 \mathrm{~L} / \mathrm{min}$; VP0940, Nitto Kohki, Tokyo, Japan) was added. The freeze-dried cake was micronized under the above conditions, which are the same conditions as for MSLI measurement. The particle size distribution was measured every $1 \mathrm{~s}$ for $8 \mathrm{~s}$ with a model 3321 APS spectrometer (TSI). In cumulative particle size distribution, the percentage of fine particles of $5 \mu \mathrm{m}$ or less was defined as APS fine particle fraction $(\mathrm{FPF}) \% \leq 5 \mu \mathrm{m}$. Each sample was measured in triplicate.

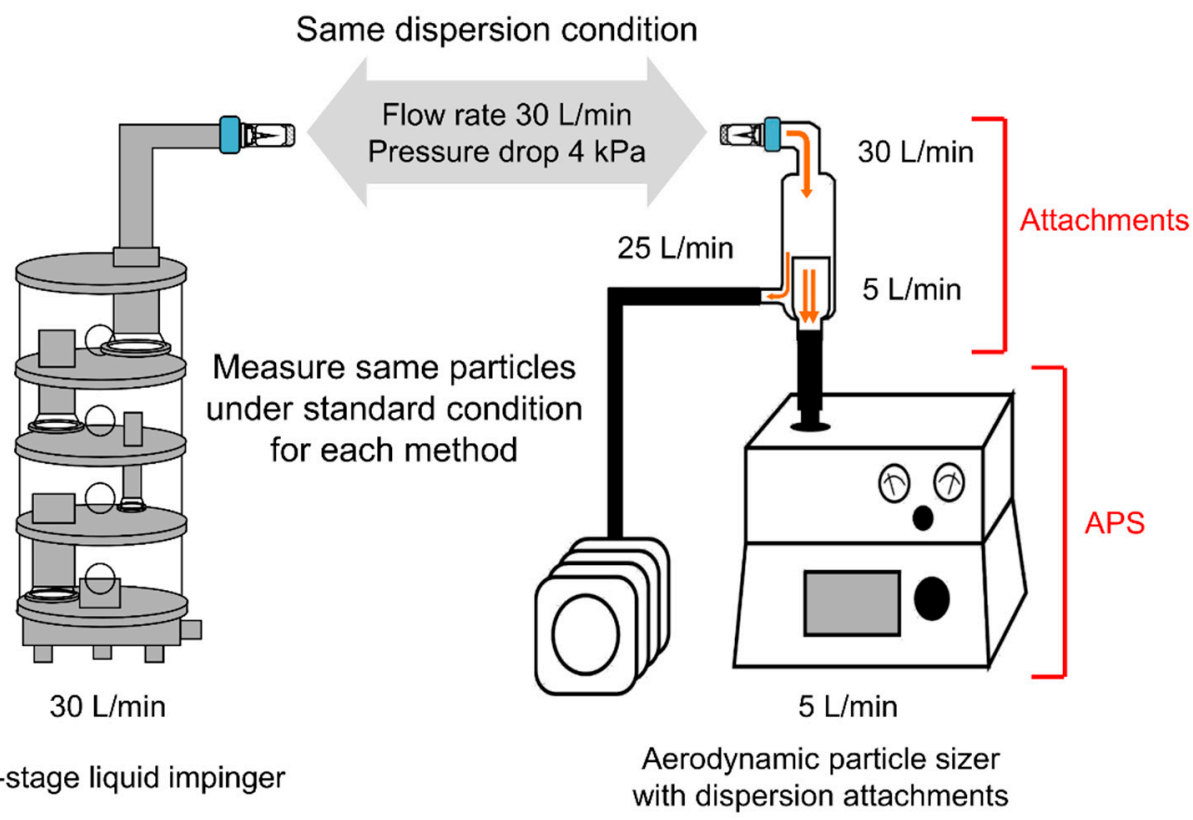

Figure 2. Methods to measure the aerodynamic particle distribution; multi-stage liquid impinger (MSLI) and aerodynamic particle sizer (APS) with dispersion attachments. Formulations are dispersed under the same condition as for MSLI measurement (flow rate of $30 \mathrm{~L} / \mathrm{min}$ at a pressure drop of $4 \mathrm{kPa}$ with the two-way needle device). Dispersed particles are measured under the standard condition for each method. In the MSLI, the aerodynamic particle size distribution is measured at a flow rate of $30 \mathrm{~L} / \mathrm{min}$ by mass. In the APS, the aerodynamic particle size distribution is measured at a flow rate of $5 \mathrm{~L} / \mathrm{min}$ based on time-of-flight theory.

\subsubsection{Inhalation Characteristic Test by Multi-Stage Liquid Impinger}

Inhalation characteristic tests were performed by MSLI. The measurement by MSLI was conducted at a flow rate of $30 \pm 0.3 \mathrm{~L} / \mathrm{min}$ with a two-way needle device (Otsuka, Tokyo, Japan) given a pressure drop of $4 \mathrm{kPa}$. The two-way needle device used in MSLI measurement was a device in clinical use (Figure 1). A vacuum pump (HCP5), critical flow controller (TPK2000), and flow meter (DFM2000) (all from Copley Scientific Limited, Nottingham, UK) were used to maintain the above condition. A hydrophilic poly(vinylidene fluoride) membrane with a diameter of $90 \mathrm{~mm}$ and retention diameter of $0.65 \mu \mathrm{m}$ (Merck Millipore, Burlington, MA, USA) was placed at stage 5 of the MSLI. Under the above condition, the freeze-dried cake was dispersed into aerosols for $8 \mathrm{~s}$. Each deposition, the experiment was repeated in triplicate. 
The diluent $(0.01 \%$ benzalkonium chloride in $10 \mathrm{mM}$ acetic acid) at each stage of the MSLI was removed for analysis. The vial, device, induction port, and membrane were each washed with the diluent. The concentration of hGhrelin derivative in the fraction recovered from the vial, the device, the induction port, and each of stages $1-5$ of the MSLI was determined by HPLC.

The MSLI FPF $\% \leq 5 \mu \mathrm{m}$ was defined as the ratio of hGhrelin derivative of $5 \mu \mathrm{m}$ or less to the emission. The proportion of hGhrelin derivative of $5 \mu \mathrm{m}$ or less was calculated by interpolation from a plot of cumulative proportion vs. effective cut-off diameter of the respective stages (at a flow rate of $30 \mathrm{~L} / \mathrm{min}$, effective cut-off diameters for stages 2, 3, and 4 were $9.6,4.4$, and $2.4 \mu \mathrm{m}$, respectively). The emission was defined as the mass ratio of the emitted dose to hGhrelin derivative content of the formulation. The emitted dose was the sum of the hGhrelin derivative mass of the induction port and each of stages 1-5 of the MSLI.

For cumulative particle distribution, the aerodynamic particle size of the cumulative percentage at $50 \%$ was defined as the mass median aerodynamic diameter (MMAD).

\subsection{Stability Tests}

To study stability in the formulation process, the hGhrelin derivative content of the prepared solution before lyophilization and that of the lyophilized cake were measured by HPLC.

To study storage stability, quantification of the hGhrelin derivative by HPLC and inhalation characteristic test by MSLI were performed using formulations stored at $25{ }^{\circ} \mathrm{C}$, $60 \%$ RH for 3 months.

\subsection{Pharmacokinetic (PK)/Pharmacodynamic (PD) Tests}

\subsubsection{Animals}

Male cynomolgus monkeys (age 5 years 9 months-6 years 3 months; weight $5.13-5.81 \mathrm{~kg}$; $\mathrm{B}$ virus free; from Cambodia) were studied. Animals were maintained under controlled temperature, humidity, and light conditions $\left(25 \pm 2{ }^{\circ} \mathrm{C}, 50 \pm 10 \% \mathrm{RH}\right.$, light on 07:00-19:00). All animal procedures were performed according to the protocol reviewed and approved by the Animal Care and Use Committee of TRANS GENIC INC. (No. 2012-4).

\subsubsection{Pulmonary Administration}

The monkeys were held in a monkey chair and anesthetized with inhalation anesthesia (oxygen $1.0 \mathrm{~L} / \mathrm{min}$, isoflurane $5 \%, 3 \mathrm{~min}$ ) only during administration. A catheter that had been kept warm at $40{ }^{\circ} \mathrm{C}$ was inserted into the trachea, and the catheter was closed with forceps except for inhalation. A device (Figure 3A) with the formulation (Figure 3B) was connected to the catheter for administration. The formulation was sprayed by handoperated air pump, and hGhrelin derivative was inhaled during the monkey's inspiration. The pulmonary administration device used for monkeys (Figure 3A) was made by the authors from a two-way needle device in clinical use (Figure 1). The LDPI formulations optimized in the optimization study were administered.

For the measurement of plasma hGhrelin derivative and GH concentrations, blood samples (approximately $2 \mathrm{~mL}$ ) were collected before and 5, 10, 20, 30, 45, 60, 90, and $120 \mathrm{~min}$ after the administration. 
A)

\section{Catheter}

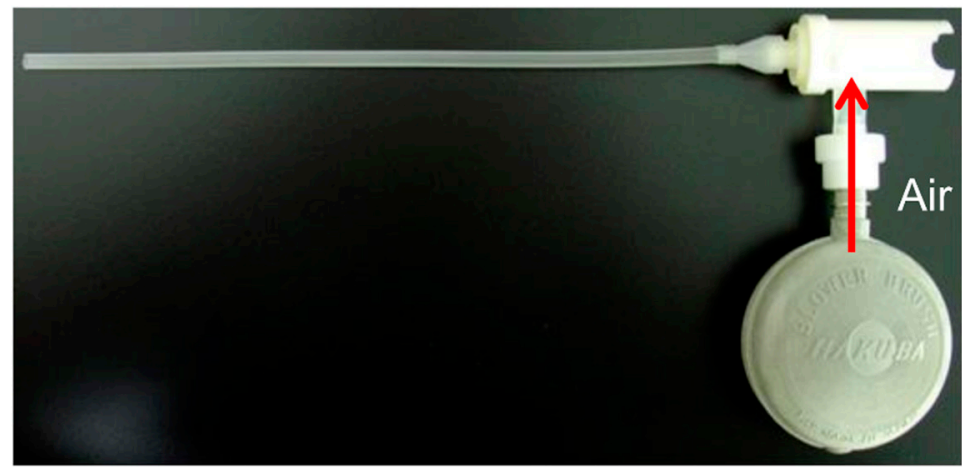

Hand-operated air pump
B)

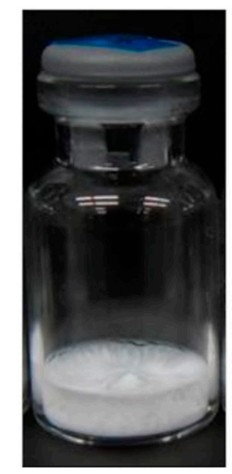

Figure 3. (A) Device used for pulmonary administration of lyophilizate for dry powder inhalation (LDPI) formulation to monkeys. (B) LDPI formulations containing $0.5 \mathrm{mg} /$ vial of hGhrelin derivative. LDPI formulations are sprayed by hand-operated air pump and inhaled during the monkey's inspiration through the catheter. The pulmonary administration device for monkeys was self-made and not for clinical use, whereas the formulations can be clinically used.

\subsubsection{Measurement of Plasma Concentration of hGhrelin Derivative}

The concentration of hGhrelin derivative in plasma was measured by the radioimmunoassay (RIA) method according to a previous study [54]. Approximately $1.2 \mathrm{~mL}$ of the collected blood sample was mixed with $24 \mu \mathrm{L}$ of $500 \mathrm{mmol} / \mathrm{L}$ Pefabloc ${ }^{\circledR}$ SC solution and $12 \mu \mathrm{L}$ of $10 \%$ EDTA saline solution and centrifuged at $4{ }^{\circ} \mathrm{C}$ at $10,000 \times g$ for $2 \mathrm{~min}$ to obtain plasma. Then, $500 \mu \mathrm{L}$ of the obtained plasma was mixed with $50 \mu \mathrm{L}$ of $1 \mathrm{~mol} / \mathrm{L}$ $\mathrm{HCl}$, and a primary antibody that recognizes the N-terminal of the hGhrelin derivative was added. The primary antibody was diluted with RIA buffer (mixture of $50 \mathrm{mmol} / \mathrm{L}$ sodium phosphate buffer [pH 7.4], 0.5\% BSA, 0.5\% Triton ${ }^{\circledR}-\mathrm{X} 100,80 \mathrm{mmol} / \mathrm{L}$ sodium chloride, $25 \mathrm{mmol} / \mathrm{L}$ EDTA, and $0.05 \%$ sodium azide) containing $0.5 \%$ standard rabbit serum. The mixture was incubated for $12 \mathrm{~h}$. Subsequently, $100 \mu \mathrm{L}$ of $\left[{ }^{125} \mathrm{I}\right]$ ligand solution $(15,000 \mathrm{cpm})$ was added, and the mixture was incubated for $36 \mathrm{~h}$. Next, $100 \mu \mathrm{L}$ of a secondary antibody (anti-rabbit immunoglobulin G goat serum) was added, and the mixture was incubated for $24 \mathrm{~h}$ followed by centrifugation at $3000 \mathrm{rpm}$ for $30 \mathrm{~min}$. After the supernatant was removed, the radioactivity of the pellet was measured by an ARC-600 $\gamma$ counter (Hitachi Aloka Medical Co., Ltd., Tokyo, Japan). The limits of detection and quantitation were $2.5 \mathrm{ng} / \mathrm{mL}$ and $14 \mathrm{ng} / \mathrm{mL}$ as the plasma concentrations, respectively.

\subsubsection{Measurement of Plasma Concentration of GH}

The plasma concentration of GH was measured by the RIA method. Plasma was obtained from approximately $0.8 \mathrm{~mL}$ of the collected blood sample in the same way as described in Section 2.7.3. The concentration of GH in the obtained plasma was measured by an ARC-600 $\gamma$ counter (Hitachi Aloka Medical Co., Ltd., Tokyo, Japan) using a human GH kit for blood test "Daiichi" (TFB, Tokyo, Japan).

\section{Results}

\subsection{Optimization of Formulations \\ 3.1.1. Selection of Excipients}

Excipients play an important role in the generation of particles suitable for inhalation in the LDPI system [45]. In comparison to saccharides, which are widely used as excipients for freeze-dried preparations, amino acids (especially hydrophobic amino acids) showed high aerosolization performance as excipients for LDPI formulations [39,45,55]. Therefore, we performed the screening study focusing not on saccharides but on hydrophobic amino acids. Visual evaluation of the cake appearance and APS measurement were performed 
using formulations containing $0.5 \mathrm{mg} /$ vial of hGhrelin derivative and hydrophobic amino acid, for which the hydropathy index is a positive value (isoleucine: 4.5, valine: 4.2, leucine: 3.8 , phenylalanine: 2.8 , methionine: 1.9 , alanine: 1.8 [56]), respectively, to select the optimum amino acid for the excipient. As shown in Figure 4, formulations with Phe added showed configuration score 2. From the result of APS measurement, formulations with Leu added showed the highest APS FPF $\% \leq 5 \mu \mathrm{m}$. The APS FPF $\% \leq 5 \mu \mathrm{m}$ values of formulations with Ile or Phe added were the second highest after Leu. Although formulations with Leu and Ile added showed high APS FPF $\% \leq 5 \mu \mathrm{m}$, these formulations showed configuration score 1 (not suitable for LDPI formulation). However, formulations with Phe added showed a high APS FPF $\% \leq 5 \mu \mathrm{m}$ and configuration score 2 .

\begin{tabular}{|c|c|c|c|c|c|c|}
\hline $\begin{array}{l}\text { Amino acid } \\
(0.5 \mathrm{mg} / \mathrm{vial})\end{array}$ & Ala & Met & Phe & Leu & Val & Ile \\
\hline Configuration & & & & & & \\
\hline Score & 1 & 1 & 2 & 1 & 1 & 1 \\
\hline
\end{tabular}

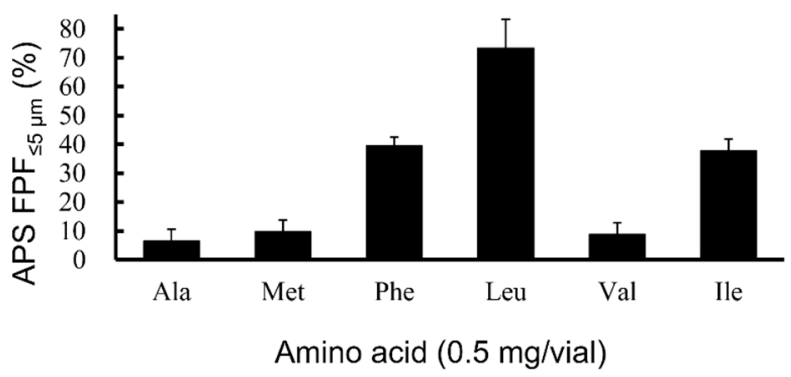

Figure 4. Effect of hydrophobic amino acids on configuration and fine particle fraction in the LDPI system. Representative photographs of formulations, configuration score, and values of APS $\mathrm{FPF} \% \leq 5 \mu \mathrm{m}$ (mean $\pm \mathrm{SD}, n=3$ ) are shown. Formulations were prepared to contain $0.5 \mathrm{mg} / \mathrm{vial}$ of hGhrelin derivative with $0.5 \mathrm{mg} /$ vial of amino acid. APS, aerodynamic particle sizer; FPF, fine particle fraction; Ala, alanine; Met, methionine; Phe, phenylalanine; Leu, leucine; Val, valine; Ile, isoleucine.

In the LDPI system, good cake appearance is necessary to ensure stable performance because LDPI formulations are aerosolized by convection flow of air in the vial. When a lyophilized cake has a poor appearance, air impact on inhalation is not equal among vials. Furthermore, the dose emitted upon inhalation can be expected to decrease due to adhesion of the cake pieces to the rubber stopper and other parts of the device. From this point, Phe, which showed both good cake appearance and high FPF $(39.5 \pm 3.0 \%)$, was considered as an optimum excipient for LDPI formulations of hGhrelin derivative.

\subsubsection{Optimization of Phe Amount in LDPI Formulation}

To study the effect of the added amount of Phe on the cake appearance and aerosolization performance, formulations containing $0.5 \mathrm{mg}$ /vial of hGhrelin derivative with $0.2,0.4$, $0.6,0.8$, or $1.0 \mathrm{mg} /$ vial of Phe were prepared. Visual evaluation of the cake appearance and APS measurement were performed. As shown in Figure 5, formulations with 0.6, 0.8, or $1.0 \mathrm{mg} /$ vial of Phe added showed configuration score 2 . The APS FPF $\% \leq 5 \mu \mathrm{m}$ value of the formulation to which $0.8 \mathrm{mg} /$ vial of Phe was added was the highest $(42.4 \pm 4.2 \%)$. Then, inhalation characteristic tests by MSLI were performed using formulations containing $0.5 \mathrm{mg} /$ vial of hGhrelin derivative with $0.8 \mathrm{mg} /$ vial of Phe because APS FPF $\%_{\leq 5} \mu \mathrm{m}$ is a surrogate benchmark for MSLI FPF $\% \leq 5 \mu \mathrm{m}$. The results of the MSLI measurements are shown in Figure 6. The MSLI FPF $\% \leq 5 \mu \mathrm{m}$ was $41.7 \pm 3.8 \%$ and the MMAD was $5.6 \pm 0.4 \mu \mathrm{m}$. 


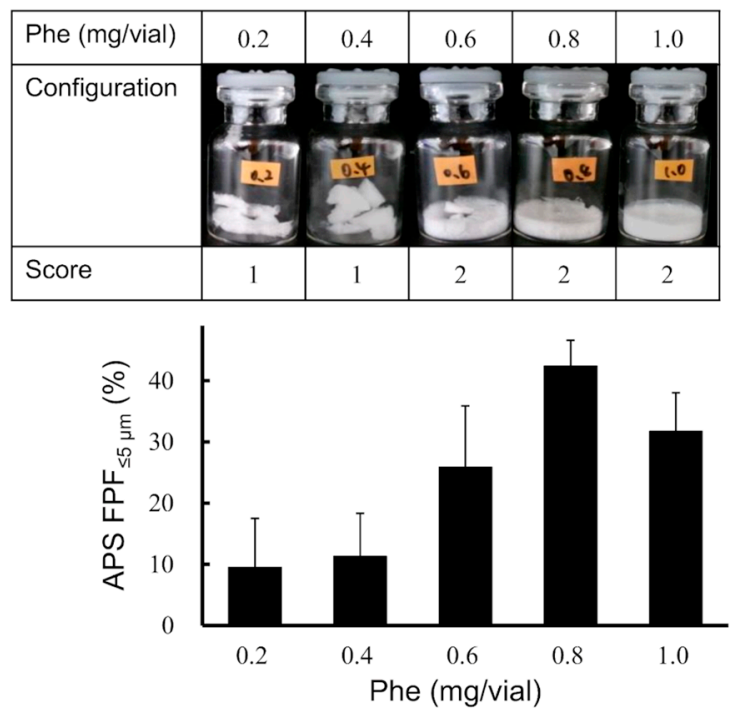

Figure 5. Optimization of the amount of Phe in the LDPI system. Representative photographs of formulations, configuration score, and values of $\mathrm{APS} F P F \% \leq 5 \mu \mathrm{m}$ (mean $\pm \mathrm{SD}, n=3$ ) are shown. Formulations were prepared to contain $0.5 \mathrm{mg} /$ vial of hGhrelin derivative with Phe.

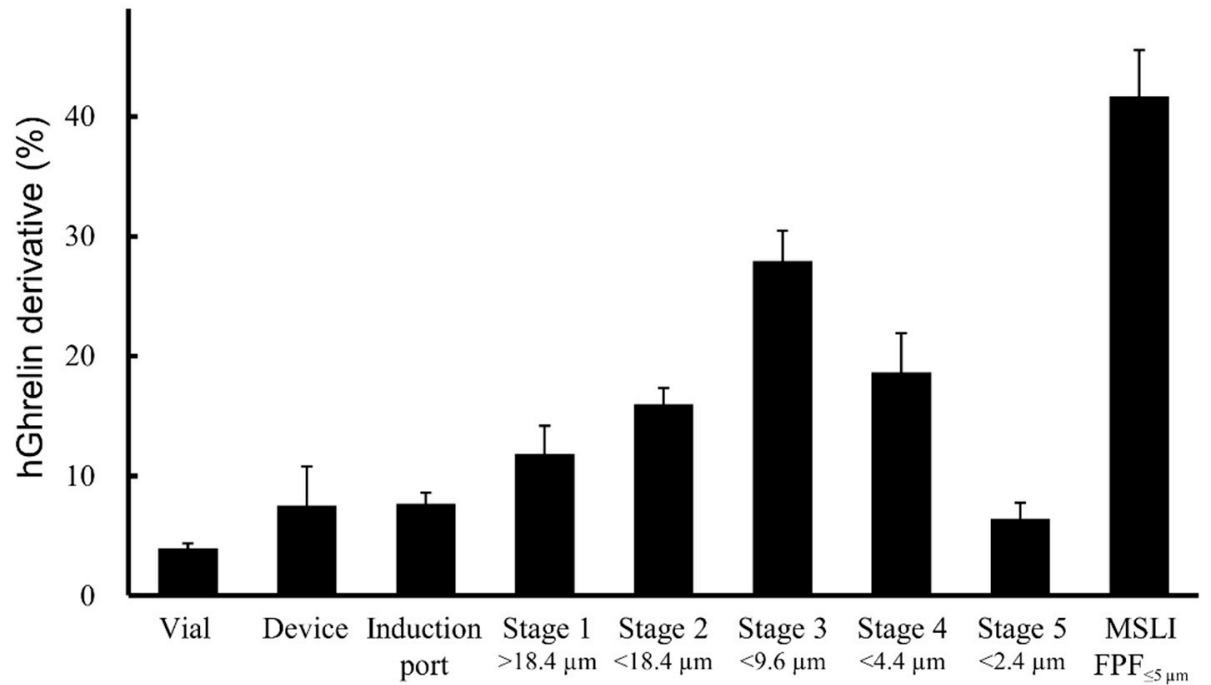

Figure 6. Distribution of aerodynamic particle size by MSLI in the optimal formulation of the LDPI system (mean $\pm \mathrm{SD}, n=3$ ). Formulations were prepared to contain $0.5 \mathrm{mg} /$ vial of hGhrelin derivative with $0.8 \mathrm{mg} /$ vial of Phe.

\subsubsection{Feasibility Evaluation of LDPI Formulation as a Preparation for PK/PD Study}

To study stability in the formulation process, the purity of the hGhrelin derivative before and after lyophilization was compared. As shown in Figure 7A, there was no significant difference.

For evaluation of storage stability, formulations containing $0.5 \mathrm{mg} /$ vial of hGhrelin derivative and $0.8 \mathrm{mg} /$ vial of Phe were stored at $25^{\circ} \mathrm{C}, 60 \% \mathrm{RH}$ for 3 months. The purity of hGhrelin derivative and MSLI FPF $\% \leq 5 \mu \mathrm{m}$ was compared between before and after storage, but there were no significant differences (Figure 7B,C). This optimal formulation is thus feasible as a preparation in the PK/PD study in monkeys. 

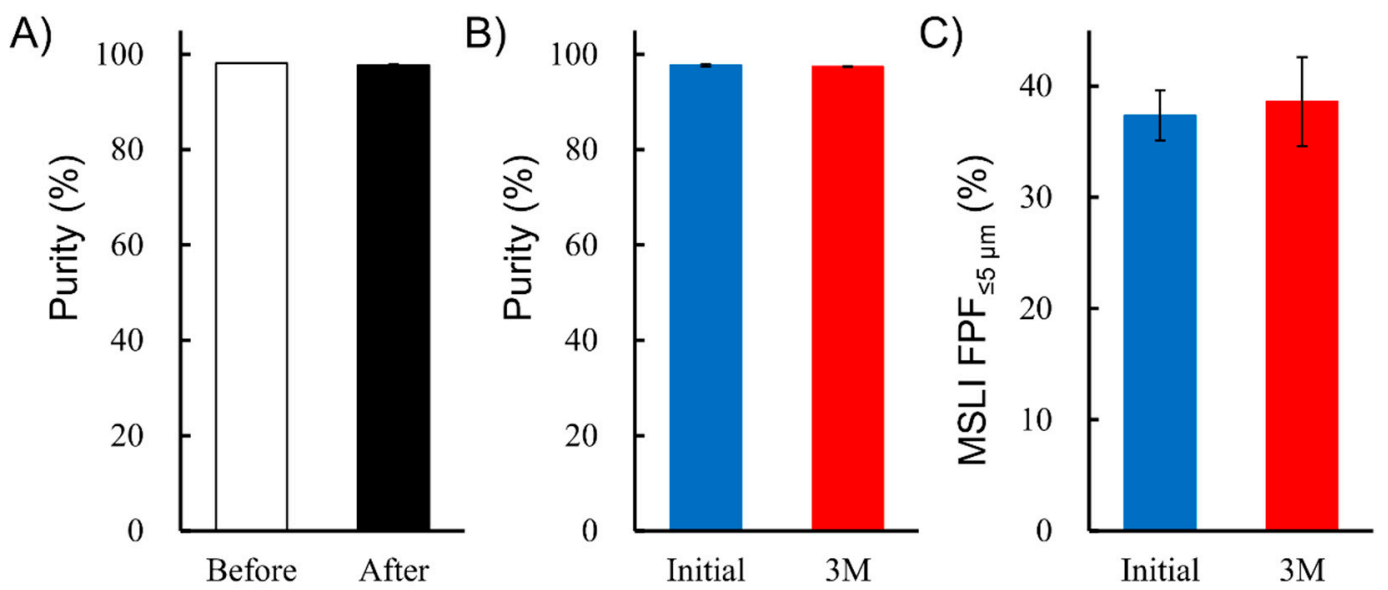

Figure 7. Feasibility evaluation of LDPI formulation as a preparation for PK/PD study. (A) Effect of lyophilization on purity of hGhrelin derivative in formulation before and after lyophilization (mean $\pm \mathrm{SD}, n=3)$. (B) Effect of storage ( 3 months at $25^{\circ} \mathrm{C}, 60 \% \mathrm{RH}$ ) on purity of hGhrelin derivative in formulation (mean $\left.\pm \mathrm{SD}, n=3\right)$. (C) Effect of storage $\left(3 \mathrm{months}\right.$ at $25^{\circ} \mathrm{C}$, $60 \% \mathrm{RH}$ ) on MSLI FPF $\% \leq 5 \mu \mathrm{m}$ in the LDPI system (mean $\pm \mathrm{SD}, n=3$ ). Formulations were prepared to contain $0.5 \mathrm{mg} / \mathrm{vial}$ of hGhrelin derivative with $0.8 \mathrm{mg} /$ vial of Phe.

\subsection{PK/PD Tests}

To study PK/PD of the hGhrelin derivative with LDPI formulation, the optimized formulation $(0.5 \mathrm{mg} / \mathrm{vial}$ of hGhrelin derivative with $0.8 \mathrm{mg} /$ vial of Phe) was pulmonary administered to monkeys.

\subsubsection{PK Tests}

Formulations containing $0.5 \mathrm{mg} /$ vial of hGhrelin derivative $(57.4 \mu \mathrm{g} / \mathrm{kg})$ were pulmonary administered, and the time profiles of the plasma concentration of hGhrelin derivative in monkeys were measured. Although the plasma concentration of hGhrelin derivative was measured from 0 to $120 \mathrm{~min}$ after administration, the time profiles from 0 to $60 \mathrm{~min}$ are shown because the concentration after $60 \mathrm{~min}$ was lower than the limit of quantitation. Furthermore, formulations containing $0.1 \mathrm{mg} / \mathrm{vial}$ of hGhrelin derivative $(13.1 \mu \mathrm{g} / \mathrm{kg})$ were pulmonary administered $(n=3)$ for comparison, but the time profiles are not shown because the plasma concentration was lower that the limit of quantitation. As shown in Figure 8, the plasma concentration of hGhrelin derivative peaked at $10 \mathrm{~min}$ after pulmonary administration. The area under the plasma concentration-time curve (AUC) was $1.8 \pm 0.4 \mu \mathrm{g} \cdot \mathrm{min} / \mathrm{mL}$ for pulmonary administration of hGhrelin derivative $(57.4 \mu \mathrm{g} / \mathrm{kg})$, whereas it was $1.7 \pm 0.1 \mu \mathrm{g} \cdot \mathrm{min} / \mathrm{mL}$ for intravenous administration $(10.0 \mu \mathrm{g} / \mathrm{kg})$. Absolute bioavailability of the inhaled hGhrelin derivative with respect to intravenous hGhrelin derivative was $16.9 \pm 2.6 \%$, assuming that the dose linearity holds for each route of administration. 


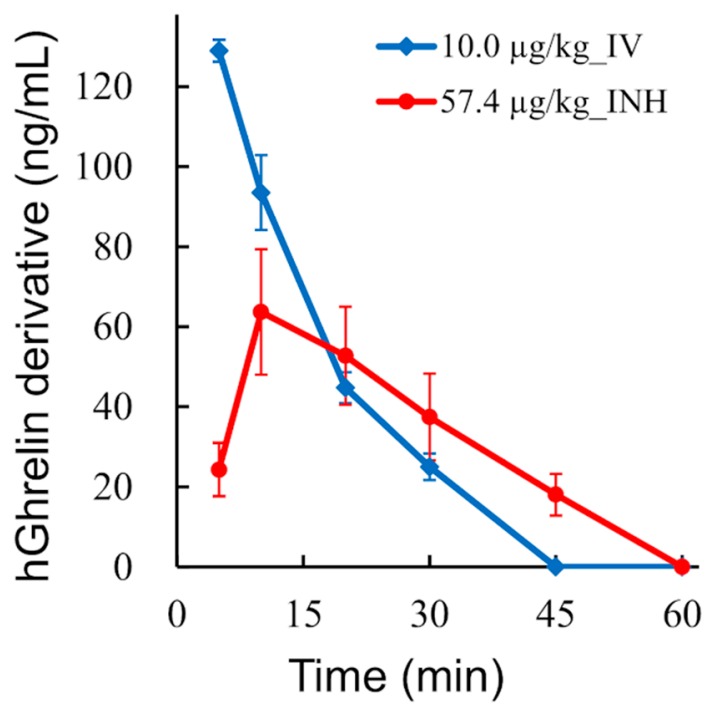

Figure 8. Pharmacokinetic profile of hGhrelin derivative of the LDPI system in monkeys (mean $\pm \mathrm{SE}$, $n=4$ ). Plasma concentration of hGhrelin derivative in monkeys treated with LDPI formulation (hGhrelin derivative $57.4 \mu \mathrm{g} / \mathrm{kg}, \bullet$ ) and monkeys intravenously administered hGhrelin derivative $(10.0 \mu \mathrm{g} / \mathrm{kg}, \diamond)$. IV, intravenous injection; INH, inhalation.

\subsubsection{PD Tests}

Formulations containing 0.1 and $0.5 \mathrm{mg} / \mathrm{vial}$ of hGhrelin derivative $(13.1$ and $57.4 \mu \mathrm{g} / \mathrm{kg}$ ) were pulmonary administered, and the time profiles of the plasma concentration of $\mathrm{GH}$ in monkeys were measured. As shown in Figure 9, the peak of the GH in plasma occurred at approximate $24 \mathrm{~min}$ after pulmonary administration of hGhrelin derivative (13.1 and $57.4 \mu \mathrm{g} / \mathrm{kg}$ ). Meanwhile, an increase of GH was shown from administration (time 0 ) to approximately $16 \mathrm{~min}$ after intravenous administration of hGhrelin derivative $(10.0 \mu \mathrm{g} / \mathrm{kg})$. The AUCs of GH were $2.1 \pm 0.6$ and $3.3 \pm 0.2 \mu \mathrm{g} \cdot \mathrm{min} / \mathrm{mL}$ for pulmonary administration of hGhrelin derivative (13.1 and $57.4 \mu \mathrm{g} / \mathrm{kg})$, whereas it was $3.4 \pm 0.5 \mu \mathrm{g} \cdot \mathrm{min} / \mathrm{mL}$ for intravenous administration.

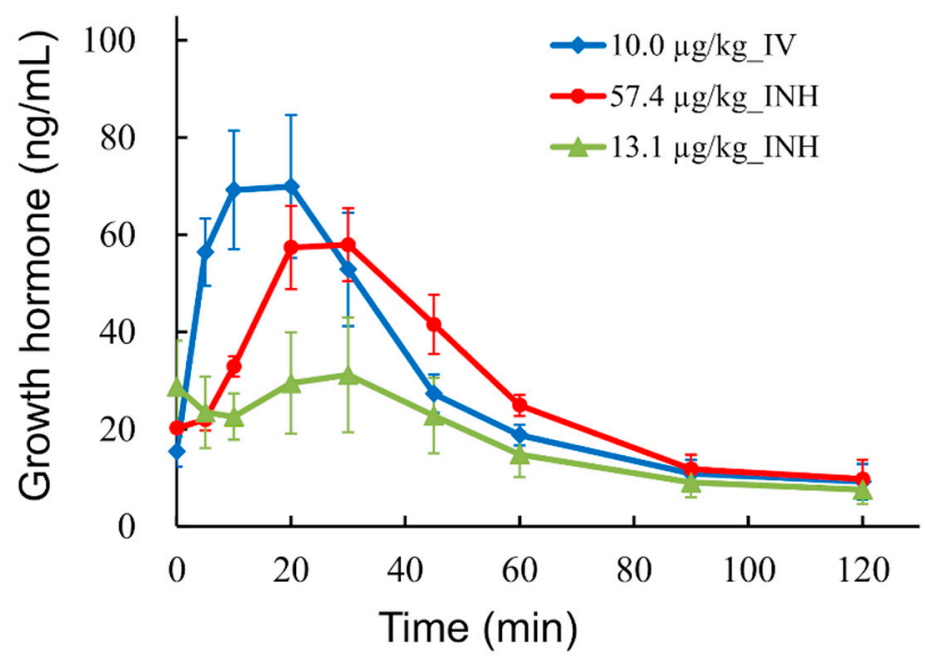

Figure 9. Pharmacodynamic profile of hGhrelin derivative of the LDPI system in monkeys (mean $\pm \mathrm{SE}, n=3$ or 4 ). Plasma concentration of growth hormone in monkeys treated with LDPI formulation (hGhrelin derivative $57.4 \mu \mathrm{g} / \mathrm{kg}, \bullet ; 13.1 \mu \mathrm{g} / \mathrm{kg}, \mathbf{\Delta}$ ) and monkeys intravenously administered hGhrelin derivative $(10.0 \mu \mathrm{g} / \mathrm{kg}, \diamond)$. IV, intravenous injection; INH, inhalation. 


\section{Discussion}

\subsection{Optimization of Formulations}

As a result of screening of the six amino acids, formulations with Leu added showed the highest FPF (Figure 4). Leu is known as a dispersibility enhancer excipient used in spray-drying of carrier-free DPI formulations [57-59]. Leu decreases the inter-particulate cohesive and adhesive forces and improves flowability and dispersibility of aerosolized particles $[60,61]$. The excipient showing the highest FPF value is selected as the most suitable excipient in optimization of the formulation for conventional DPIs because aerosolization performance is the key characteristic. However, the LDPI formulation is prepared as not particles but a lyophilized cake as shown in Figure 1. In the LDPI system, a lyophilized cake is aerosolized just upon inhalation by air impact. When the cake appearance is poor, aerosolization performance on inhalation may fluctuate due to static generation among fragmented pieces of the cake [62]. In other words, good cake appearance is necessary to guarantee stable aerosolization performance of LDPI formulations. Thus, excipients that show both high FPF and good cake appearance should be selected as the suitable excipient in optimization of LDPI formulations. Lyophilizate of an LDPI formulation is broken into pieces by air impact and aerosolized by the convection flow of air in the vial. Then, porous particles reconstructed from pieces of lyophilizate are emitted through the device. When a lyophilized cake has a poor appearance, air impact is diffused, which may cause insufficient disintegration of the lyophilized cake, and air impact on inhalation is not equal among vials. Furthermore, aerosolization performance may be non-constant because a static electrical charge is generated among fragmented pieces of lyophilizate. In addition, the dose emitted upon inhalation can be expected to decrease due to adhesion of the cake pieces to the rubber stopper and other parts of the device. Thus, excipients for LDPI formulations require both good cake appearance and high FPF. In general, good cake appearance and high FPF are not compatible. In practice, formulations with Leu added showed poor cake appearance with high FPF (Figure 4). Therefore, leucine was considered to be undesirable as an excipient for LDPI formulations. From the above, we selected phenylalanine as the excipient to optimize LDPI formulations of the hGhrelin derivative.

Phe showed both good cake appearance and high FPF. In the screening study, the APS $\mathrm{FPF} \% \leq 5 \mu \mathrm{m}$ value of the formulation with Phe added was approximately $40 \%$ (Figure 4). In addition, formulations with Phe added showed higher FPF when the cake appearance was good than when the cake appearance was poor (Figure 5). In the LDPI system, it is considered that hydrophobic amino acids show high aerosolization performance due to their surface activity. Unlike saccharides, hydrophobic amino acids with surface activity tend to coordinate at the ice/water and air/water interfaces during freezing, thus forming a hydrophobic coating film that covers the porous matrix structure of the lyophilized cake. This film may cause the high aerosolization performance. Phe has higher surface activity than other hydrophobic amino acids [63] and is an aromatic amino acid. Presence of a side chain with aromatic ring is considered one of the reasons for good cake appearance. An aromatic side chain was reported to show higher glass transition temperature due to the stacking interaction [64]. High glass transition temperature is one of the important factors that contributes to good cake appearance [53]. Therefore, it is considered that Phe may show both good cake appearance and high FPF due to its aromatic side chain and surface activity.

As a result of the study of the effect of the added amount of Phe, the optimized formulation of hGhrelin derivative $(0.5 \mathrm{mg} / \mathrm{vial})$ was prepared with $0.8 \mathrm{mg} / \mathrm{vial}$ of Phe (Figure 5). MSLI FPF $\% \leq 5 \mu \mathrm{m}$, an index of the efficiency at which a formulation can reach the lungs, of the optimized formulations was approximately $40 \%$ (Figure 6). The difference between MSLI FPF $\%_{\leq 5} \mu \mathrm{m}$ and APS FPF $\% \leq 5 \mu \mathrm{m}$ was within $1.0 \%$. Our simple method using APS (Figure 2) was shown to be useful as a surrogate method for MSLI to optimize a formulation in a short time.

The stability tests showed no significant difference in the purity of the hGhrelin derivative assessed before and after lyophilization (Figure 7A). This means that LDPI can 
solve the problem of degradation and denaturation due to shear stress or high temperature during the manufacturing process of conventional DPIs, as expected.

\subsection{Prospect for Clinical Application}

The optimized formulation for PK/PD $(0.5 \mathrm{mg} /$ vial of hGhrelin derivative with $0.8 \mathrm{mg} / \mathrm{vial}$ of Phe) was pulmonary administered to monkeys and pulmonary absorption was evaluated. In vivo models of large animals are desirable to study pulmonary PK with formulation and/or device efficiency for prediction of the human PK profile $[65,66]$. As pulmonary administration methods for animals, intratracheal instillation or aerosol exposure is commonly used $[66,67]$. In the aerosol exposure method, the dose determination and absorption from extra-lung (nose and gastrointestinal tract) should be a concern in the PK analysis [68]. In contrast, intratracheal instillation can deliver a controlled quantity of drug directly into the lungs [66]. The use of sprayers such as the Pen Century dry powder insufflator are known as a method to administer powder aerosols of DPI intratracheally $[69,70]$. In the method using a sprayer, powders are loaded into the chamber of an insufflator device and delivered with additional air. However, the LDPI formulation consists not of particles but of a freeze-dried cake. Hence, we made a device to administer LDPI formulations for human clinical use intratracheally to monkeys so that pulmonary absorption with the efficiency of LDPI formulations could be evaluated.

As a result of the PK tests, the absolute bioavailability of inhaled hGhrelin derivative with respect to intravenously injected hGhrelin derivative was calculated to be about $17 \%$ assuming that the dose linearity holds for each route of administration. The absolute bioavailability of the Afrezza ${ }^{\circledR}$ (insulin inhaler) was $14.7 \%$ in human [71]. Pulmonary absorption of hGhrelin derivative with the LDPI system was expected to be comparable with a commercial DPI for systemic delivery.

In the PD tests, the time profiles of the plasma concentration of GH in monkeys were measured. Plasma GH increase is one of the markers used to detect the effect of ghrelin through GHSR [5,72]. The AUC of GH for inhalation (hGhrelin derivative $57.4 \mu \mathrm{g} / \mathrm{kg}$ ) roughly agreed with that for intravenous injection. However, the onset time of the GH increase was approximately $10 \mathrm{~min}$ later when hGhrelin derivative was pulmonary administered rather than intravenously injected (Figure 9). Inhaled hGhrelin derivative was absorbed through the lungs and then penetrated the systemic circulation leading to GH release. The plasma concentration of hGhrelin derivative peaked at $10 \mathrm{~min}$ after pulmonary administration (Figure 8), and the peak time was equal to the delay time of the $\mathrm{GH}$ increase. Thus, the delay of GH increase was considered to be due to absorption and distribution of the inhaled hGhrelin derivative. Comparing the AUCs of GH for inhalation, the AUC was about 1.6 times higher for $57.4 \mu \mathrm{g} / \mathrm{kg}$ of hGhrelin derivative administered than for $13.1 \mu \mathrm{g} / \mathrm{kg}$. Although GH release increased depending on the administered dose of hGhrelin derivative, the difference in the GH AUC by administered dose was smaller than expected. There are two possible reasons for this result. One is the ceiling effect. In previous studies $[19,73,74]$, the AUC of GH in healthy humans was about 1.3-1.6 times higher when $5 \mu \mathrm{g} / \mathrm{kg}$ of ghrelin was intravenously injected versus $1 \mu \mathrm{g} / \mathrm{kg}$ because of the ceiling effect. The other is physical stress. GH is known to be secreted in response to physical stress [75]. It is undeniable that physical stress was involved in the GH increase after pulmonary administration of hGhrelin derivative, but it was considered that the GH increase was mainly caused by inhaled hGhrelin derivative based on the onset time delay and AUC ratio.

From the results of the PK/PD tests, LDPI formulations of hGhrelin derivative may be expected to be used for systemic application by the pulmonary route.

\section{Conclusions}

In this study, we conducted PK/PD tests in monkeys using a LDPI formulation to evaluate its feasibility for systemic delivery of hGhrelin derivative. LDPI formulations for PK/PD tests were optimized by the addition of Phe $(0.5 \mathrm{mg} / \mathrm{vial}$ of hGhrelin derivative 
with $0.8 \mathrm{mg} /$ vial of Phe). The MSLI FPF $\% \leq 5 \mu \mathrm{m}$ value of the formulation used in the PK/PD tests was $41.7 \pm 3.8 \%$. In the PK tests, the AUC was $1.8 \pm 0.4 \mu \mathrm{g} \cdot \mathrm{min} / \mathrm{mL}$ for pulmonary administration of hGhrelin derivative $(57.4 \mu \mathrm{g} / \mathrm{kg})$, whereas it was $1.7 \pm 0.1 \mu \mathrm{g} \cdot \mathrm{min} / \mathrm{mL}$ for intravenous administration $(10.0 \mu \mathrm{g} / \mathrm{kg})$. In the PD tests, the AUCs of GH were $2.1 \pm 0.6$ and $3.3 \pm 0.2 \mu \mathrm{g} \cdot \mathrm{min} / \mathrm{mL}$ for pulmonary administration of hGhrelin derivative (13.1 and $57.4 \mu \mathrm{g} / \mathrm{kg}$ ), whereas it was $3.4 \pm 0.5 \mu \mathrm{g} \cdot \mathrm{min} / \mathrm{mL}$ for intravenous administration. GH release increased depending on the dose of hGhrelin derivative, although the difference in AUCs was smaller than expected. Furthermore, the onset time of the GH increase was approximately $10 \mathrm{~min}$ later when hGhrelin derivative was pulmonary administered rather than intravenously injected, and the delay time of the GH increase was equal to the peak time of hGhrelin derivative by pulmonary administration. It was considered that inhaled hGhrelin derivative was absorbed through the lungs and then penetrated the systemic circulation leading to GH release. From the above, LDPI formulations of hGhrelin derivative may be expected to be used for systemic application by the pulmonary route to treat diseases such as eating disorders and cachexia.

Supplementary Materials: The following are available online at https:/ /www.mdpi.com/1999-492 3/13/2/233/s1, Figure S1: Chemical structure of hGhrelin derivative.

Author Contributions: Conceptualization, C.Y.; Methodology, K.M., Y.I. and C.Y.; Validation, K.M. and Y.I.; Formal Analysis, K.M. and Y.I.; Investigation, K.M.; Data Curation, K.M.; Writing-Original Draft Preparation, K.M.; Writing—Review \& Editing, T.A. and C.Y.; Visualization, K.M. and T.A.; Supervision, C.Y.; Project Administration, C.Y. All authors have read and agreed to the published version of the manuscript.

Funding: This research received no external funding.

Institutional Review Board Statement: The study was conducted according to the ARRIVE guidelines and approved by the Animal Care and Use Committee of TRANS GENIC INC. (No. 2012-4).

Informed Consent Statement: Not applicable.

Data Availability Statement: The data presented in this study are available on request from the corresponding author.

Acknowledgments: The authors are grateful to K. Nobori, T. Hanada and Y. Kanai for technical assistance with the experiments.

Conflicts of Interest: The authors declare no conflict of interest.

\section{References}

1. Khatib, N.; Gaidhane, S.; Gaidhane, A.M.; Khatib, M.; Simkhada, P.; Gode, D.; Zahiruddin, Q.S. Ghrelin: Ghrelin as a Regulatory Peptide in Growth Hormone Secretion. J. Clin. Diagn. Res. 2014, 8, MC13-MC17. [CrossRef] [PubMed]

2. Hotta, M.; Ohwada, R.; Akamizu, T.; Shibasaki, T.; Takano, K.; Kangawa, K. Ghrelin Increases Hunger and Food Intake in Patients with Restricting-Type Anorexia Nervosa: A Pilot Study. Endocr. J. 2009, 56, 1119-1128. [CrossRef]

3. Mihalache, L.; Gherasim, A.; Niţă, O.; Ungureanu, M.C.; Pădureanu, S.S.; Gavril, R.S.; Arhire, L.I. Effects of Ghrelin in Energy Balance and Body Weight Homeostasis. Hormones 2016, 15, 186-196. [CrossRef]

4. Kojima, M.; Hosoda, H.; Date, Y.; Nakazato, M.; Matsuo, H.; Kangawa, K. Ghrelin Is a Growth-Hormone-Releasing Acylated Peptide from Stomach. Nature 1999, 402, 656-660. [CrossRef]

5. Sun, Y.; Wang, P.; Zheng, H.; Smith, R.G. Ghrelin Stimulation of Growth Hormone Release and Appetite Is Mediated through the Growth Hormone Secretagogue Receptor. Proc. Natl. Acad. Sci. USA 2004, 101, 4679-4684. [CrossRef] [PubMed]

6. Kojima, M.; Kangawa, K. Ghrelin: Structure and Function. Physiol. Rev. 2005, 85, 495-522. [CrossRef] [PubMed]

7. Tanaka, M.; Hayashida, Y.; Iguchi, T.; Nakao, N.; Nakai, N.; Nakashima, K. Organization of the Mouse Ghrelin Gene and Promoter: Occurrence of a Short Noncoding First Exon. Endocrinology 2001, 142, 3697-3700. [CrossRef]

8. Kaiya, H.; Kojima, M.; Hosoda, H.; Koda, A.; Yamamoto, K.; Kitajima, Y.; Matsumoto, M.; Minamitake, Y.; Kikuyama, S.; Kangawa, K. Bullfrog Ghrelin Is Modified by N-Octanoic Acid at Its Third Threonine Residue. J. Biol. Chem. 2001, 276, 40441-40448. [CrossRef] [PubMed]

9. Kaiya, H.; Van Der Geyten, S.; Kojima, M.; Hosoda, H.; Kitajima, Y.; Matsumoto, M.; Geelissen, S.; Darras, V.M.; Kangawa, K. Chicken Ghrelin: Purification, CDNA Cloning, and Biological Activity. Endocrinology 2002, 143, 3454-3463. [CrossRef] [PubMed] 
10. Shiimura, Y.; Horita, S.; Hamamoto, A.; Asada, H.; Hirata, K.; Tanaka, M.; Mori, K.; Uemura, T.; Kobayashi, T.; Iwata, S.; et al. Structure of an Antagonist-Bound Ghrelin Receptor Reveals Possible Ghrelin Recognition Mode. Nat. Commun. 2020, 11, 4160. [CrossRef] [PubMed]

11. Müller, T.D.; Nogueiras, R.; Andermann, M.L.; Andrews, Z.B.; Anker, S.D.; Argente, J.; Batterham, R.L.; Benoit, S.C.; Bowers, C.Y.; Broglio, F.; et al. Ghrelin. Mol. Metab. 2015, 4, 437-460. [CrossRef] [PubMed]

12. Date, Y.; Murakami, N.; Kojima, M.; Kuroiwa, T.; Matsukura, S.; Kangawa, K.; Nakazato, M. Central Effects of a Novel Acylated Peptide, Ghrelin, on Growth Hormone Release in Rats. Biochem. Biophys. Res. Commun. 2000, 275, 477-480. [CrossRef]

13. Hosoda, H.; Kojima, M.; Kangawa, K. Ghrelin and the Regulation of Food Intake and Energy Balance. Mol. Interv. 2002, 2, 494-503. [CrossRef]

14. Dimaraki, E.V.; Jaffe, C.A. Role of Endogenous Ghrelin in Growth Hormone Secretion, Appetite Regulation and Metabolism. Rev. Endocr. Metab. Disord. 2006, 7, 237-249. [CrossRef] [PubMed]

15. Colldén, G.; Tschöp, M.H.; Müller, T.D. Therapeutic Potential of Targeting the Ghrelin Pathway. Int. J. Mol. Sci. 2017, 18, 798. [CrossRef]

16. Nakazato, M.; Murakami, N.; Date, Y.; Kojima, M.; Matsuo, H.; Kangawa, K.; Matsukura, S. A Role for Ghrelin in the Central Regulation of Feeding. Nature 2001, 409, 194-198. [CrossRef] [PubMed]

17. Yamada, C.; Iizuka, S.; Nahata, M.; Hattori, T.; Takeda, H. Vulnerability to Psychological Stress-Induced Anorexia in Female Mice Depends on Blockade of Ghrelin Signal in Nucleus Tractus Solitarius. Br. J. Pharmacol. 2020, 177, 4666-4682. [CrossRef] [PubMed]

18. Schalla, M.A.; Stengel, A. The Role of Ghrelin in Anorexia Nervosa. Int. J. Mol. Sci. 2018, 19, 2117. [CrossRef]

19. Akamizu, T.; Takaya, K.; Irako, T.; Hosoda, H.; Teramukai, S.; Matsuyama, A.; Tada, H.; Miura, K.; Shimizu, A.; Fukushima, M.; et al. Pharmacokinetics, Safety, and Endocrine and Appetite Effects of Ghrelin Administration in Young Healthy Subjects. Eur. J. Endocrinol. 2004, 150, 447-455. [CrossRef]

20. Miki, K.; Maekura, R.; Nagaya, N.; Nakazato, M.; Kimura, H.; Murakami, S.; Ohnishi, S.; Hiraga, T.; Miki, M.; Kitada, S.; et al. Ghrelin Treatment of Cachectic Patients with Chronic Obstructive Pulmonary Disease: A Multicenter, Randomized, Double-Blind, Placebo-Controlled Trial. PLoS ONE 2012, 7, e35708. [CrossRef]

21. Antosova, Z.; Mackova, M.; Kral, V.; Macek, T. Therapeutic Application of Peptides and Proteins: Parenteral Forever? Trends Biotechnol. 2009, 27, 628-635. [CrossRef]

22. Bajracharya, R.; Song, J.G.; Back, S.Y.; Han, H.-K. Recent Advancements in Non-Invasive Formulations for Protein Drug Delivery. Comput. Struct. Biotechnol. J. 2019, 17, 1290-1308. [CrossRef]

23. Agarwal, V.; Khattry, V.; Biswas, G.R.; Majee, S.B. Protein and Peptide Drug Delivery: By Noninvasive Technology. Res. J. Pharm. Biol. Chem. Sci. 2017, 470-476.

24. Hay, P.J.; Touyz, S.; Claudino, A.M.; Lujic, S.; Smith, C.A.; Madden, S. Inpatient versus Outpatient Care, Partial Hospitalisation and Waiting List for People with Eating Disorders. Cochrane Database Syst. Rev. 2019, 1, CD010827. [CrossRef] [PubMed]

25. Halmi, K.A.; Agras, W.S.; Crow, S.; Mitchell, J.; Wilson, G.T.; Bryson, S.W.; Kraemer, H.C. Predictors of Treatment Acceptance and Completion in Anorexia Nervosa: Implications for Future Study Designs. Arch. Gen. Psychiatry 2005, 62, 776-781. [CrossRef] [PubMed]

26. Von Brachel, R.; Hötzel, K.; Hirschfeld, G.; Rieger, E.; Schmidt, U.; Kosfelder, J.; Hechler, T.; Schulte, D.; Vocks, S. Internet-Based Motivation Program for Women with Eating Disorders: Eating Disorder Pathology and Depressive Mood Predict Dropout. J. Med. Internet Res. 2014, 16, e92. [CrossRef] [PubMed]

27. Bodell, L.P.; Keel, P.K. Current Treatment for Anorexia Nervosa: Efficacy, Safety, and Adherence. Available online: https://www. dovepress.com/current-treatment-for-anorexia-nervosa-efficacy-safety-and-adherence-peer-reviewed-article-PRBM (accessed on 10 October 2020).

28. Wallier, J.; Vibert, S.; Berthoz, S.; Huas, C.; Hubert, T.; Godart, N. Dropout from Inpatient Treatment for Anorexia Nervosa: Critical Review of the Literature. Int. J. Eat. Disord. 2009, 42, 636-647. [CrossRef] [PubMed]

29. Dejong, H.; Broadbent, H.; Schmidt, U. A Systematic Review of Dropout from Treatment in Outpatients with Anorexia Nervosa. Int. J. Eat. Disord. 2012, 45, 635-647. [CrossRef]

30. National Collaborating Centre for Mental Health (UK). Eating Disorders: Core Interventions in the Treatment and Management of Anorexia Nervosa, Bulimia Nervosa and Related Eating Disorders; National Institute for Health and Clinical Excellence: Guidance; British Psychological Society (UK): Leicester, UK, 2004; ISBN 978-1-85433-398-8.

31. Pandaya, S.; Misra, A. Inhalable glucagon-like peptide 1 porous particles prepared by spray freeze drying technique. J. Aerosol Med. Pulm. Drug Deliv. 2016, 29 , A16.

32. Owens, D.R. New Horizons-Alternative Routes for Insulin Therapy. Nat. Rev. Drug Discov. 2002, 1, 529-540. [CrossRef]

33. Patton, J.S.; Byron, P.R. Inhaling Medicines: Delivering Drugs to the Body through the Lungs. Nat. Rev. Drug Discov. 2007, 6, 67-74. [CrossRef] [PubMed]

34. Sahane, S.; Nikhar, A.; Bhaskaran, S.; Mundhada, D. Dry Powder Inhaler: An Advance Technique for Pulmonary Drug Delivery System. Int. J. Pharm. Chem. Sci. 2012, 1, 1376-1383.

35. Yang, M.Y.; Chan, J.G.Y.; Chan, H.-K. Pulmonary Drug Delivery by Powder Aerosols. J. Control. Release 2014, 193, 228-240. [CrossRef] [PubMed]

36. Johnson, K.A. Preparation of Peptide and Protein Powders for Inhalation. Adv. Drug Deliv. Rev. 1997, 26, 3-15. [CrossRef] 
37. Pilcer, G.; Amighi, K. Formulation Strategy and Use of Excipients in Pulmonary Drug Delivery. Int. J. Pharm. 2010, $392,1-19$. [CrossRef] [PubMed]

38. Depreter, F.; Pilcer, G.; Amighi, K. Inhaled Proteins: Challenges and Perspectives. Int. J. Pharm. 2013, 447, 251-280. [CrossRef]

39. Yamashita, C.; Ibaragi, S.; Fukunaga, Y.; Akagi, A. Composition, Vessel, Dry Powder Inhalation System, and Related Methods for Transpulmonary Administration. Patent US-7448379, 11 November 2008.

40. Yamashita, C.; Fukunaga, Y.; Akagi, A. Dry Powder Inhalation System for Transpulmonary Administration. Patent US-7735485, 15 June 2010.

41. Yamashita, C.; Matsushita, H.; Ibaragi, S.; Akagi, A. Inhalation Device for Transpulmonary Administration. Patent US-7708014, 4 May 2010.

42. Yamashita, C. Low Flow Rate-Dependent Dry Powder Inhalation System Using Freeze-Dried Cake. J. Pharm. Sci. Technol. Jpn. 2012, 72, 111-116. [CrossRef]

43. Yamashita, C. Development of Otsuka Dry Powder Inhalation System Using Technology of Freeze-Drying. Drug Deliv. Syst. 2009, 24, 468-476. [CrossRef]

44. Miyamoto, K.; Taga, H.; Akita, T.; Yamashita, C. Simple Method to Measure the Aerodynamic Size Distribution of Porous Particles Generated on Lyophilizate for Dry Powder Inhalation. Pharmaceutics 2020, 12, 976. [CrossRef]

45. Ohori, R.; Kiuchi, S.; Sugiyama, S.; Miyamoto, K.; Akita, T.; Yamashita, C. Efficient Optimization of High-Dose Formulation of Novel Lyophilizates for Dry Powder Inhalation by the Combination of Response Surface Methodology and Time-of-Flight Measurement. Int. J. Pharm. 2020, 581, 119255. [CrossRef]

46. De Vriese, C.; Gregoire, F.; Lema-Kisoka, R.; Waelbroeck, M.; Robberecht, P.; Delporte, C. Ghrelin Degradation by Serum and Tissue Homogenates: Identification of the Cleavage Sites. Endocrinology 2004, 145, 4997-5005. [CrossRef]

47. Shanado, Y.; Kometani, M.; Uchiyama, H.; Koizumi, S.; Teno, N. Lysophospholipase I Identified as a Ghrelin Deacylation Enzyme in Rat Stomach. Biochem. Biophys. Res. Commun. 2004, 325, 1487-1494. [CrossRef]

48. Matsumoto, M.; Matsumoto, M.; Hanada, T.; Wakabayashi, N. Liquid Preparation of Physiologically Active Peptide. Patent US-8969298, 3 March 2005.

49. Dong, Z.X.; Shen, Y. Ghrelin Analogs. Patent US-7589058, 15 September 2009.

50. Matsumoto, M.; Hosoda, H.; Kitajima, Y.; Morozumi, N.; Minamitake, Y.; Tanaka, S.; Matsuo, H.; Kojima, M.; Hayashi, Y.; Kangawa, K. Structure-Activity Relationship of Ghrelin: Pharmacological Study of Ghrelin Peptides. Biochem. Biophys. Res. Commun. 2001, 287, 142-146. [CrossRef]

51. Zemenova, J.; Sykora, D.; Adamkova, H.; Maletinska, L.; Elbert, T.; Marek, A.; Blechova, M. Novel Approach to Determine Ghrelin Analogs by Liquid Chromatography with Mass Spectrometry Using a Monolithic Column. J. Sep. Sci. 2017, 40, 1032-1039. [CrossRef]

52. Staes, E.; Rozet, E.; Učakar, B.; Hubert, P.; Préat, V. Validation of a Method for the Quantitation of Ghrelin and Unacylated Ghrelin by HPLC. J. Pharm. Biomed. Anal. 2010, 51, 633-639. [CrossRef]

53. Patel, S.M.; Nail, S.L.; Pikal, M.J.; Geidobler, R.; Winter, G.; Hawe, A.; Davagnino, J.; Rambhatla Gupta, S. Lyophilized Drug Product Cake Appearance: What Is Acceptable? J. Pharm. Sci. 2017, 106, 1706-1721. [CrossRef] [PubMed]

54. Hosoda, H.; Kojima, M.; Matsuo, H.; Kangawa, K. Ghrelin and Des-Acyl Ghrelin: Two Major Forms of Rat Ghrelin Peptide in Gastrointestinal Tissue. Biochem. Biophys. Res. Commun. 2000, 279, 909-913. [CrossRef]

55. Claus, S.; Schoenbrodt, T.; Weiler, C.; Friess, W. Novel Dry Powder Inhalation System Based on Dispersion of Lyophilisates. Eur. J. Pharm. Sci. 2011, 43, 32-40. [CrossRef]

56. Mitaku, S.; Hirokawa, T.; Tsuji, T. Amphiphilicity Index of Polar Amino Acids as an Aid in the Characterization of Amino Acid Preference at Membrane-Water Interfaces. Bioinformatics 2002, 18, 608-616. [CrossRef] [PubMed]

57. Seville, P.C.; Learoyd, T.P.; Li, H.-Y.; Williamson, I.J.; Birchall, J.C. Amino Acid-Modified Spray-Dried Powders with Enhanced Aerosolisation Properties for Pulmonary Drug Delivery. Powder Technol. 2007, 178, 40-50. [CrossRef]

58. Barazesh, A.; Gilani, K.; Rouini, M.; Barghi, M.A. Effect of $\mathrm{pH}$ and leucine concentration on aerosolization properties of carrier-free formulations of levofloxacin. Eur. J. Pharm. Sci. 2018, 118, 13-23. [CrossRef]

59. Otake, H.; Okuda, T.; Okamoto, H. Development of Spray-Freeze-Dried Powders for Inhalation with High Inhalation Performance and Antihygroscopic Property. Chem. Pharm. Bull. 2016, 64, 239-245. [CrossRef]

60. Otake, H.; Okuda, T.; Hira, D.; Kojima, H.; Shimada, Y.; Okamoto, H. Inhalable Spray-Freeze-Dried Powder with L-Leucine That Delivers Particles Independent of Inspiratory Flow Pattern and Inhalation Device. Pharm. Res. 2016, 33, 922-931. [CrossRef] [PubMed]

61. Chew, N.Y.K.; Shekunov, B.Y.; Tong, H.H.Y.; Chow, A.H.L.; Savage, C.; Wu, J.; Chan, H.-K. Effect of Amino Acids on the Dispersion of Disodium Cromoglycate Powders. J. Pharm. Sci. 2005, 94, 2289-2300. [CrossRef]

62. Kaialy, W. A Review of Factors Affecting Electrostatic Charging of Pharmaceuticals and Adhesive Mixtures for Inhalation. Int. J. Pharm. 2016, 503, 262-276. [CrossRef]

63. Watry, M.R.; Richmond, G.L. Orientation and Conformation of Amino Acids in Monolayers Adsorbed at an Oil/Water Interface as Determined by Vibrational Sum-Frequency Spectroscopy. J. Phys. Chem. B 2002, 106, 12517-12523. [CrossRef]

64. Fukumoto, K.; Yoshizawa, M.; Ohno, H. Room Temperature Ionic Liquids from 20 Natural Amino Acids. J. Am. Chem. Soc. 2005, 127, 2398-2399. [CrossRef] [PubMed] 
65. Sakagami, M. In Vitro, Ex Vivo and in Vivo Methods of Lung Absorption for Inhaled Drugs. Adv. Drug Deliv. Rev. 2020, in press. [CrossRef]

66. Guillon, A.; Sécher, T.; Dailey, L.A.; Vecellio, L.; de Monte, M.; Si-Tahar, M.; Diot, P.; Page, C.P.; Heuzé-Vourc'h, N. Insights on Animal Models to Investigate Inhalation Therapy: Relevance for Biotherapeutics. Int. J. Pharm. 2018, 536, 116-126. [CrossRef] [PubMed]

67. Nahar, K.; Gupta, N.; Gauvin, R.; Absar, S.; Patel, B.; Gupta, V.; Khademhosseini, A.; Ahsan, F. In Vitro, in Vivo and Ex Vivo Models for Studying Particle Deposition and Drug Absorption of Inhaled Pharmaceuticals. Eur. J. Pharm. Sci. 2013, 49, 805-818. [CrossRef]

68. Sakagami, M. In Vivo, in Vitro and Ex Vivo Models to Assess Pulmonary Absorption and Disposition of Inhaled Therapeutics for Systemic Delivery. Adv. Drug Deliv. Rev. 2006, 58, 1030-1060. [CrossRef]

69. Guillon, A.; Montharu, J.; Vecellio, L.; Schubnel, V.; Roseau, G.; Guillemain, J.; Diot, P.; de Monte, M. Pulmonary Delivery of Dry Powders to Rats: Tolerability Limits of an Intra-Tracheal Administration Model. Int. J. Pharm. 2012, 434, 481-487. [CrossRef]

70. Grainger, C.I.; Alcock, R.; Gard, T.G.; Quirk, A.V.; van Amerongen, G.; de Swart, R.L.; Hardy, J.G. Administration of an Insulin Powder to the Lungs of Cynomolgus Monkeys Using a Penn Century Insufflator. Int. J. Pharm. 2004, 269, 523-527. [CrossRef] [PubMed]

71. Drug Approval Data of FDA. Afrezza (Insulin Human) Inhalation Powder. Application No. 022472. Available online: https: / / www.accessdata.fda.gov/drugsatfda_docs/nda/2014/022472Orig1s000TOC.cfm (accessed on 9 November 2020).

72. Mansson, J.V.; Alves, F.D.; Biolo, A.; Souza, G.C. Use of Ghrelin in Cachexia Syndrome: A Systematic Review of Clinical Trials. Nutr. Rev. 2016, 74, 659-669. [CrossRef] [PubMed]

73. Hataya, Y.; Akamizu, T.; Takaya, K.; Kanamoto, N.; Ariyasu, H.; Saijo, M.; Moriyama, K.; Shimatsu, A.; Kojima, M.; Kangawa, K.; et al. A Low Dose of Ghrelin Stimulates Growth Hormone (GH) Release Synergistically with GH-Releasing Hormone in Humans. J. Clin. Endocrinol. Metab. 2001, 86, 4552-4555. [CrossRef] [PubMed]

74. Takaya, K.; Ariyasu, H.; Kanamoto, N.; Iwakura, H.; Yoshimoto, A.; Harada, M.; Mori, K.; Komatsu, Y.; Usui, T.; Shimatsu, A.; et al. Ghrelin Strongly Stimulates Growth Hormone Release in Humans. J. Clin. Endocrinol. Metab. 2000, 85, 4908-4911. [CrossRef] [PubMed]

75. Desborough, J.P. The Stress Response to Trauma and Surgery. Br. J. Anaesth. 2000, 85, 109-117. [CrossRef] 